DOI 10.14526/2070-4798-2018-13-4-80-86

\title{
Health saving technologies in prevention of students harmful habits
}

\author{
Marina M. Shubovich, Elizaveta A. Grineva, Nadezhda V. Bibikova \\ Ulyanov State Pedagogical University, Ulyanovsk, Russia \\ ODCID: oooo-Ooo2-8325-8626, shubmm@mail.ru \\ eliz.grin9@yandex.ru,nv95@rambler.ru
}

\begin{abstract}
The authors justify the relevance of the study. They note that at present, the preservation and strengthening of health is one of the main strategic objectives of the country development. It is evidenced by statistical data on the health status in different regions of Russia. Materials. The essence of the basic concepts: "health", "healthy lifestyle", "health-saving technologies", "prevention of bad habits" was clarified as starting materials and the analysis of the main definitions was carried out. Methods. The study was conducted on the basis of the Ulyanov State Pedagogical University, Ulyanovsk with students of the Pedagogy and Psychology Faculty. The purpose of the study was to implement a social program for the prevention of students harmful habits in the conditions of the university through health-saving technologies "We choose health." To identify the level of students' attitude to a healthy lifestyle, the method "Express-diagnostics of valuable ideas about a healthy lifestyle" (Yu.V. Naumenko) and author's questionnaire "The presence of bad habits" was used. Results. The study showed that the program activities contributed to the formation of useful skills of a healthy lifestyle, a sense of responsibility for their lives, awareness of the life value. Control diagnosis indicates a decrease in the propensity for bad habits and positive changes in attitudes towards a healthy lifestyle. Conclusion. The study of the health-saving technologies role in the prevention of harmful habits in the future can serve as the basis for further comprehensive research on the problem of shaping a healthy lifestyle for students. They help to preserve and develop biological, psychological and physiological functions, optimal working ability and social activity of a person.
\end{abstract}

Key words: health, healthy lifestyle, health-saving technologies, bad habits, prevention.

For citation: Marina M. Shubovich, Elizaveta A. Grineva, Nadezhda V. Bibikova. Health saving technologies in the prevention of addictions student youth. The Russian Journal of Physical Education and Sport. 2018; 13 (4): 67-71. DOI 10.14526/2070-4798-2018-13-4-80-86

\section{Introduction}

The problem of health preservation acts as a global inseparable from other problems of mankind. Today everyone is united in the fact that the health of the population is the main condition for the prosperity of Russia. The task of preserving, strengthening and developing health, the formation of the values of a healthy lifestyle and a conscious attitude towards it is a priority in the policy of the Russian state [1,9].

The main factors reducing the standard of living are the deterioration of the demographic, ecological, socio-economic situation, as well as insufficient prevention of alcoholism, drug addiction, and smoking. In this regard, the number of people in need of medical, psychological and pedagogical support is increasing. Today, the preservation and strengthening of health is one of the main strategic objectives of the country's development. It is regulated and provided by such legal documents as the Law of the Russian Federation "On Education in the Russian Federation", "On Sanitary and Epidemiological Well-Being of the Population", as well as Decrees of the Russia President "On Urgent Measures directions of state social policy to improve the situation of children in the Russian Federation”, etc.

According to the World Health Organization, drug addiction, especially among young people, has reached a critical level. One of the most pressing problems of our time is the abuse of tobacco products. Statistics show that more than 5 million people die every year due to excessive smoking. In Russia, over the past 10 years, $40 \%$ of boys and $17 \%$ of girls have been smoking [2].

According to statistics, in the Ulyanovsk region over the past 3 years, alcohol consumes almost 28\% of Ulyanovsk youth, occasionally use alcoholic beverages - about $15 \% .43 \%$ of boys and $30 \%$ of girls have a predilection for smoking. $12 \%$ of children smokers tried the first cigarette before the age of 12 years. At the 
same time, $94 \%$ of adolescents are well aware of the harm they cause to their own body. A special role in solving the problem of preventing bad habits belongs to health-saving technologies.

The aim of the study was the theoretical substantiation of the students harmful habits preventing problem and the practical implementation of the program through health-saving technologies.

Materials and research methods. The essence of the basic concepts: "health", "healthy lifestyle", "health-saving technologies", "prevention" was clarified as starting materials. We will analyze the main definitions.

Modern philosophers, responding to the question: "What is the place of a person in the world?", Believe that a person has absolute value, and therefore his life and health are existential values [3].

In accordance with this approach, we consider individual health as a complex system, which is a combination of bodily, mental, spiritual components and connections between them.

Currently, there are more than 300 definitions of the concept "health". According to the definition of the World Health Organization, health is a state of complete physical, mental and social well-being, and not only the absence of diseases or physical defects [4,14].

In addition, the concept of "health" contains an idea of the harmony and power of an open bioenergy information system, which is a person. This system interacts with environmental and social environmental factors, transforming which, inevitably, is itself subject to their influence [5].

Health is a process of preserving and developing biological, mental and physiological functions, optimal working ability and social activity of a person with the maximum duration of his active life. Health primarily depends on lifestyle [6].

A healthy lifestyle unites everything that contributes to the fulfillment by a person professional, social, family and household functions in optimal health conditions and determines the direction of an individual's efforts in preserving and strengthening individual and public health. A healthy lifestyle is a complex of recreational activities, forms and methods of everyday cultural activity of an individual, manifested in physical activity, proper nutrition, hardening, in compliance with work and rest schedules, giving up bad habits [7].

An important role in the formation of a healthy lifestyle belongs to health-saving technologies.

The term "health-saving educational technologies" can be viewed as a qualitative characteristic of any educational technology, its "safety certificate for health", and as a combination of the principles, techniques, methods of pedagogical work that, complementing traditional technologies of training and education, endow them with a sign of health.

Health-saving educational technologies are psychological and pedagogical technologies, programs, methods that are aimed at educating students of health culture, personal qualities that contribute to its preservation and strengthening, the idea of health as a value formation, the motivation to lead a healthy lifestyle $[8,10,11]$.

Higher education institutions pay great attention to health issues. The health of a young person, his socio-psychological adaptation, and normal development are largely determined by the environment in which he lives. The implementation of health-saving technologies should be understood as health protection. It is understood as the formation, promotion of health, education of health culture, the desire to competently take care of their health. Health for each person is the condition of his active full and long life, success in all spheres of life, full social functioning.

Research methods: theoretical analysis, testing, questioning, data processing methods. The study was conducted on the basis of the Ulyanov State Pedagogical University, Ulyanovsk in 2018. The study involved 65 students of the Pedagogy and Psychology Faculty. The age of the subjects 18-19 years.

During the learning process, students should have a scientific understanding of the health and a healthy lifestyle essence; attitude to health as a value; holistic view of man. They should have skills to 
manage their health in the field of bad habits and addictions prevention, as well as various diseases. They understand the essence of these phenomena. This process is based on the implementation of health-saving technologies [9].

The implementation of health-saving technologies in the university is primarily associated with the formation of a healthy lifestyle and the prevention of bad habits that affect the mental and physical state of the body. Formation of a healthy lifestyle is not limited only to propaganda and certain types of medical and social activities. A healthy lifestyle is formed by all parties and manifestations of society. For the establishment of a healthy lifestyle, it is not enough to focus only on overcoming the risk factors of various diseases: fight against alcoholism, smoking, physical inactivity, poor nutrition, conflict relations. Although this also has great health value. A healthy lifestyle is the basis of prevention [10].

Today, the formation of a healthy lifestyle among young professionals working in education is of particular importance. The success of a healthy lifestyle at a young age depends on how successfully it forms and consolidates in consciousness, interfering with or promoting the development of a person's potential. Young people are most susceptible to various formative or educational influences. On the other hand, at this age there is already a basis for the manifestation of conscious individual activity in ensuring a healthy lifestyle in their wards [12].

Work in this direction also allows in the future to neutralize the development of risk factors for various diseases. It helps to teach young teachers to prevent the occurrence of bad habits in the younger generation. One of the components of lifestyle are habits.

Habit is a person's need to perform certain actions in certain conditions. According to the mechanism of action, the habit is an automated way to perform any actions that have been consolidated as a result of their repeated repetition [13].

Harmful habits are those habits that have a negative impact on mental health, human health, social behavior. They prevent people from achieving active longevity. Bad habits can be directed:

- on itself (violation of the diet: anorexia, bulimia; hypodynamia);

- on themselves and others (smoking, alcoholism, drug addiction);

- on others (passive smoking, antisocial behavior) [14].

Bad habits (tobacco smoking, alcohol use, drug addiction) are a complex behavioral act. In the emergence and development of them not only physiological factors take part, but also a whole complex of social and psychological conditions, it is necessary to develop theoretical and practical approaches to giving up bad habits, and also the creation and large-scale implementation of preventive programs.

Prevention of bad habits is traditionally divided into three stages.

The first is the primary prevention, which is inherent in avoiding the abuse of harmful habits before the abuse in general has a chance to occur.

Secondary prophylaxis deals with already started abuse. This type of prevention is similar to early treatment when problems just surfaced.

The third form of prevention, which is called tertiary, is the treatment of people who already have bad habits and dependence on them [14].

According to many authors, preventive work is the creation of conditions for the formation of sustainable attitudes among young people in the rejection of alcohol, narcotic substances, and smoking. The main objective of prevention is to prevent the occurrence of the desire to try them. To do this, young people must be successfully implemented in the outside world: to be able to solve problems that have arisen, to meet the needs, using their knowledge and abilities [14].

The purpose of the empirical research was to implement a social program for the prevention of students harmful habits in the university through health-saving technologies. As the main principles of pedagogical prevention of harmful habits among students, the following were identified: the principle of expediency, consistency, differentiation and axiology, strategic integrity, multidimensionality. 


\section{Results and Discussion}

At the first stage, ascertaining diagnostics was carried out using a diagnostic technique and an author questionnaire.

1. To identify the level of attitudes towards a healthy lifestyle, the method "Express-diagnostics of valuable ideas about a healthy lifestyle" (Yu.V. Naumenko) was used.

This technique allowed to determine the levels of value attitude to health: high - personalityoriented type; above average - the level of conscious attitude to health (resource-pragmatic type); medium - insufficiently conscious attitude to health (adaptation-supporting type); low - the lack of a conscious attitude to their health as a value.

At the ascertaining stage, $12 \%$ of students have a high level of attitude towards a healthy lifestyle, $21 \%$ of students are above average, $49 \%$ have an average level, and $18 \%$ have a low level. Based on the data obtained, it can be concluded that the majority of students have not sufficiently formed a conscious attitude towards a healthy lifestyle.

2. Author's questionnaire "The presence of bad habits."

The results of the survey showed that the majority of students are aware of the detrimental effect of bad habits on life, many respondents acknowledge the presence of harmful addictions in themselves. Many students want to get rid of bad habits and make efforts for this. In the answers to the question about the presence of bad habits, respondents took the first place as lazy - 75\%, followed by Internet addiction (62\%), smoking (43\%), using obscene expressions (27\%), excessive food intake (24\%), alcohol abuse (13\%). Most of the respondents have information about positive measures to combat bad habits.

Taking into account the results obtained in the course of ascertaining diagnostics, at the second stage a social program was developed and implemented for the prevention of students harmful habits by means of health-saving technologies "We choose health".

The program for the prevention of students bad habits in a higher educational institution is aimed at training skills aimed at preserving and strengthening one's health, as well as at preventing bad habits through the implementation of health-saving technologies.

\section{The program included two blocks:}

Block 1. Activities aimed at improving attitudes towards healthy lifestyles (exercise "Learning healthy lifestyle", training "Health and healthy lifestyles", talk "We want to be healthy", playing "Yes! Healthy lifestyles", debate "What do you mean?" to be healthy?".

Block 2. Events for the prevention of bad habits (creating a collage "The Tree of Life", exercise "Decision We Make", game "Causes and Effects", quest "The Road to a New Life", lecture "The Alphabet of Prevention", video contest "Physical Culture and Sport in our life. "

\section{Conclusion}

Thus, author's preventive program in the general system educational activities of the educational institution was aimed to solve problems of bad habits prevention (primary prevention). Cognitive component of preventive work was taken into account in various forms of mass, group and individual psycho-pedagogical activities (game methods, training work, life situations theatricalization, etc.), determining the content and preventive focus technology education in the university conditions.

The results of the test diagnostics showed positive changes in attitudes towards a healthy lifestyle. It also reduced the percentage of students with a tendency to addictions.

The program activities contributed to the formation of a healthy lifestyle useful skills, a sense of responsibility of students for their lives, and an awareness of the life value. It was shaping a healthy lifestyle among student youth behavioral strategies and personal resources. They impede the occurrence of bad habits. They develop young people social maturity. It creats conditions for communication. It develops personal 
qualities that contribute to the formation of highly efficient constructive behavior.

\section{References}

1. Spirin V.K., Smirnova L.V., Chupekhina O.A. Realization of the school health function based on the actualization of the educational environment pedagogical potential. Theory and practice of physical culture $=$ Teoriay I praktika fizicheskoj kul'tury. 2017; 5: 19-20 (in Russ., in Engl.).

2. Zinoviev N.A., Bavykin E.A. Health in the system of value orientations of students in the context of sports activities. Theory and practice of physical culture = Teoriay I praktika fizicheskoj kul'tury. 2017; 5: 19-20 (in Russ., in Engl.).

3. Karabaeva S.I., Zakharova L.M., Andrianova E.I., Shubovich M.M. Readiness of students of pedagogical university for health-saving activities in the pre-school educational organization. Theory and practice of physical culture = Teoriay I praktika fizicheskoj kul'tury. 2018; 2: 18-20 (in Russ., in Engl.).

4. Puzanova Zh.V., Tertyshnikova A.G. Peculiarities of lifestyle and attitudes towards the health of Russian students (on the example of MSU and RUDN). Sociologicheskie issledovaniya. 2017; 8: 88-94 (in Russ.).

5. Shinkevich V..Ye., Korobitsina T.V. Evaluation of the condition, the main determinants and prevention of drug use in the Krasnoyarsk region. Sociologicheskie issledovaniya. 2018; 2: 152-158 (in Russ.). 2006: 258.

6. Barinova A.N. Pedagogical aspects of prevention of bad habits in young men. Candidate's thesis.

7. Valyukh M.N., Golev N.V.. Diagnostics of the health-oriented orientation of the individual. Innovacionnye proekty I programmy $v$ obrazovanii. 2011; 5: 13-15 (in Russ.).

8. Merenkov A.V., Sushchenko A.D. The needs of university students in additional education: features of the formation and implementation. Voprosy obrazovaniya. 2016; 3: 204-223 (in Russ.).

9. Ekaterina A. Fedorova, Valeri G. Shubovich, Igor O. Petrishchev. Creative Activity Development of Students from Physical Culture and Sports Faculty on the Basis of TRIZ-Pedagogy. Pedagogikopsihologicheskie I mediko-biologicheskie problemy fizicheskoj kul'tury I sporta = Pedagogicopsychological medico-biological problems of physical culture and sport. 2016; 11 (3): 111-115. DOI: 10.14526 / 01_1111_136 (in Russ., in Engl.).

10. American College of Sports Medicine. Physical activity programmes and behavior counseling in older adult populations. Medicine and Science in Sports and Exercise. 2004; 36(11): 1997-2003.

11. Bauman A.E. Physical activity and exercise programs. Physical activity and health. 2007: 319334.

12. Biddle S.J.H., Atkin A., Cavill N., Foster C. Correlates of physical activity in youth: A review of quantitative systematic reviews. International Review of Sport and Exercise Psychology. 2011; 4(1): 25-49.

13. Bize R., Johnson J.A., Plotnikoff R.C. Physical activity level and health-related quality of life in the general adult population: A systematic review. Preventive Medicine. 2007; 45(6): 401-415.

14. Brehm W., Wagner P., Sygusch R., Hahn U., Janke A. Health Promotion by means of Health Sport. A framework and a controlled intervention study with sedentary adults. Scandinavian Journal of Medicine and Science in Sports. 2005; 15(1): 13-20.

\section{Submitted: o3.11.2018}

\section{Author's information:}

Marina M. Shubovich - Doctor of Pedagogics, Associate Professor, Ulyanov State Pedagogical University, Ulyanovsk, Russia, Lenin Square, House 4/5, 432071, e-mail: shubmm@mail.ru

Elizaveta A. Grineva - Candidate of Pedagogics, Associate Professor, Ulyanov State Pedagogical University, Ulyanousk, Russia, Lenin Square, House 4/5, 432071, e-mail: eliz.gring@yandex.ru

Nadezhda V. Bibikova - Candidate of Pedagogics, Ulyanov State Pedagogical University, Ulyanovsk, Russia, Lenin Square, House 4/5, 432071, e-mail:nv95@rambler.ru 